\title{
Older patients' experiences with a shared decision-making process on choosing dialysis or conservative care for advanced chronic kidney disease: a survey study
}

Wouter R. Verberne ${ }^{1 *}\left(\mathbb{D}\right.$, Wanda S. Konijn², Karen Prantl' ${ }^{2}$ Janneke Dijkers' ${ }^{1}$, Margriet T. Roskam', Johannes J. M. van Delden ${ }^{3}$ and Willem Jan W. Bos ${ }^{1,4}$

\begin{abstract}
Background: Many older patients approaching end-stage kidney disease have to decide whether to go for dialysis or non-dialytic conservative care (CC). Shared decision-making is recommended to align the treatment plan with the patient's preferences and values. Little is known about older patients' experiences with shared decision-making on dialysis or CC.

Methods: We performed a survey study, in collaboration with the Dutch Kidney Patients Association, in 99 patients aged $\geq 70$ years who had chosen dialysis $(n=75)$ or CC $(n=24)$ after a shared decision-making process involving an experienced multidisciplinary team.

Results: Patients stated to be overall satisfied with the shared decision-making process (\% with score 6-10 on 11point Likert scale, dialysis versus CC: $93 \%$ vs. $91 \%, P=0.06)$, and treatment decision ( $87 \%$ vs. $91 \%, P=0.03)$. However, patients also reported negative experiences, especially those who had chosen dialysis. Such negative experiences were related to the timing, informing, and level of decision-making being shared. More patients who selected dialysis indicated to have felt forced to make a decision, mostly due to the circumstances, such as their deteriorating health or kidney function, or by their nephrologist ( $31 \%$ vs. $5 \%, P=0.01$ ). Also, patients who selected dialysis mentioned a perceived lack of choice as most common reason for choosing dialysis, and $55 \%$ considered their own opinion as most important rather than their nephrologists' or relatives' opinion compared to $90 \%$ of the patients who had chosen CC ( $P=0.02)$. A subset of patients who had chosen dialysis still doubted their treatment decision compared to no patient who had chosen CC (17\% vs. $0 \%, P=0.03)$.
\end{abstract}

Conclusions: Older patients reported contrasting experiences with shared decision-making on dialysis or CC. Despite high overall satisfaction, the underlying negative experiences illustrate important but modifiable barriers to an optimal shared decision-making process.

Keywords: Shared decision making, Chronic kidney failure, Renal dialysis, Conservative treatment, Aged

\footnotetext{
* Correspondence: w.verberne@antoniusziekenhuis.nl

'Department of Internal Medicine, St Antonius Hospital, Koekoekslaan 1, 3435

CM Nieuwegein, The Netherlands

Full list of author information is available at the end of the article
}

(c) The Author(s). 2019 Open Access This article is distributed under the terms of the Creative Commons Attribution 4.0 International License (http://creativecommons.org/licenses/by/4.0/), which permits unrestricted use, distribution, and reproduction in any medium, provided you give appropriate credit to the original author(s) and the source, provide a link to the Creative Commons license, and indicate if changes were made. The Creative Commons Public Domain Dedication waiver (http://creativecommons.org/publicdomain/zero/1.0/) applies to the data made available in this article, unless otherwise stated. 


\section{Background}

An increasing number of older patients has advanced chronic kidney disease (CKD) [1, 2]. These patients, who often are frail, have comorbid conditions and decreased independence $[3,4]$, are being considered for dialysis, which has become the most common treatment pathway for end-stage kidney disease in older patients. Dialysis is an intensive treatment that patients, their family, and clinicians might consider as too burdensome, outweighing the benefits. Non-dialytic conservative care (CC) has been recognized as reasonable alternative [5]. The main goal of a multidisciplinary CC pathway is to preserve quality of life instead of longevity. There is growing evidence from observational studies that dialysis may not prolong life or improve quality of life compared to $\mathrm{CC}$ in older patients, particularly in the oldest old and those with severe comorbidity [6-10].

Recent guidelines recommend shared decision-making as model to decide on preferred treatment in patients with advanced CKD [5, 11-14]. The main goal of shared decision-making is to align the treatment plan with the patient's preferences and values by having discussions between patient and professional to come to a joint decision. Although the new guidelines help clinicians to do so, there is ongoing debate how the shared decisionmaking process on dialysis or CC should take place. For example, what timing is best to initiate decision-making [15-17], what factors influence patient and professional decision-making $[16,18]$, and how to properly counsel and involve older patients [17, 19-21]. Furthermore, in shared decision-making both patients and clinicians need to understand what considerations are important for the other.

The professionals' perspectives on treatment decisionmaking in older patients with advanced CKD have been studied relatively well. These studies found that nephrologists attach most value to the patient's preferences, followed by comorbidity, cognitive function, and physical function [22, 23]. Other studies, however, showed that nephrologists predominantly base the decision whether to start dialysis on biomedical factors and a tendency to prolong life [18], that they struggle to explain disease trajectory and prognosis [21, 24-26], and that nephrologists differ in their interpretation and approach to patient engagement [20].

Little is known about the views of older patients with advanced CKD on shared decision-making for choosing dialysis or CC. Several studies have explored reasons of older patients for their treatment choice [27-31], but only three included both patient groups who either had chosen dialysis or CC [32-34]. Furthermore, older patients' experiences with, and preferences for, shared decision-making on dialysis or CC are still largely unexplored, particularly of patients who chose CC $[16,18]$.
Better understanding of these aspects for both patient groups may help to improve shared decision-making processes and patient-centered care. Therefore, the aim of our survey was to assess and compare older patients' experiences with, and preferences for, a shared decisionmaking process on dialysis or $\mathrm{CC}$.

\section{Methods}

In collaboration with the Dutch Kidney Patients Association, two patient representatives and a policy adviser were involved in designing the study and questionnaire. They performed an anonymous systematic evaluation of our research protocol using an assessment form developed by the Association.

\section{Participants}

Patients with stage $4 / 5$ CKD aged $\geq 70$ years who had chosen dialysis or $\mathrm{CC}$ after a shared decision-making process were recruited from a previously identified cohort in a non-academic teaching hospital in The Netherlands [8]. Patients of this cohort alive in 2015 and 2016 were asked to participate during a routine hospital visit or by phone. Exclusion criteria were mental incapacitation or language problems of such severity that the informed consent procedure or the questionnaire could not be completed. Written informed consent was obtained from all included patients. The local research ethics committee waived the need for ethical approval.

\section{Shared decision-making process}

An experienced multidisciplinary team of nephrologists, nephrology nurses, social workers, and dieticians was involved in the shared decision-making process on preferred treatment. As part of standard care, the nephrologist initiated the process when the patient's kidney function dropped $<20 \mathrm{~mL} / \mathrm{min} / 1.73 \mathrm{~m}^{2}$ by making the patient and family aware of the need for a decision. This was followed by in-depth discussions with the patient and family on preferred treatment, during which oral and written information were given about practicalities, benefits, and risks of the different treatment modalities including dialysis and CC. Each shared decision-making process was tailored to the individual patient recognizing the patient's needs and preferences in making a decision. Alongside the regular outpatient visits, standard but not obligatory components offered to all patients included a one-hour counselling and education session about possible treatment by the nephrology nurse, and a visit to the patient's home by the social worker. Patients were also invited to visit the dialysis unit. Finally, a decision on preferred treatment was made during a consultation with the nephrologist, which was defined in the study as 'original treatment decision' and based on the recording note in the medical record. This decision was regularly 
evaluated and patients always had the opportunity to change their original decision.

In patients choosing hemodialysis or peritoneal dialysis, dialysis treatment was prepared and initiated once needed. We defined the dialysis group as all patients who had chosen for the intention to start dialysis after the shared decision-making process (ie, choice for dialysis-group), comprising both pre-dialysis patients and those who started with dialysis. In patients choosing $\mathrm{CC}$, active medical treatment and multidisciplinary care were continued.

\section{Questionnaire}

The questionnaire was newly developed to assess experiences and preferences of older patients related to their shared decision-making process on dialysis or $\mathrm{CC}$, and to explore reasons for their treatment choice. Input on the questionnaire-including content, appropriateness of wording, and clarity-was generated from the literature and from the multidisciplinary team involved in counselling (nephrologists, nurses, social workers), an ethicist, two patient representatives, and a policy advisor of the Dutch Kidney Patients Association to establish content validity. Main topics to be assessed were the patient's level of preparedness for shared decision-making, the timing of the decision-making, its informing, the level of decision-making being shared, and the patient's satisfaction with the shared decision-making process and treatment decision. The final version consisted of 27 questions, including: binary questions (yes/no); questions with a 11-point Likert scale, categorised into: positive (score 6-10), neutral (score 5), or negative answer (score $0-4)$; and open-ended questions (Additional file 1). Additional questions were included to determine marital status, religion, and education level [35].

\section{Data collection and analyses}

The questionnaire was completed by patients at a selfchosen moment, or administered by a researcher (WV, JD) during a hospital visit. Data collected from electronic medical records included: age, sex, comorbidity, time since original treatment decision (defined as time between recording note of original treatment decision after the shared decision-making process in the medical record, and taking part in the survey), and number of consultations about preferred treatment between patient and healthcare team. Comorbidity was scored according to the Davies comorbidity score [36], which is based on the presence of seven comorbid conditions producing three risk groups: no comorbidity (score 0), intermediate comorbidity (score 1 or 2 ), and severe comorbidity (score $\geq 3$ ). Descriptive statistics were used including the unpaired $t$, chi-squared, Fisher-Freeman-Halton, and Mann-Whitney U test. A $P$ value $<0.05$ was considered statistically significant. Statistical analyses were performed using IBM SPSS Statistics 24.0. Open text responses were independently categorised into themes by two researchers (WV, JD), followed by discussions within the research team-including a patient representative-to reach consensus.

\section{Results}

Of 128 eligible patients, 99 (77\%) consented and answered the questionnaire: 75 who had chosen dialysis, and 24 CC after the shared decision-making process. The median time between original treatment decision and the survey was 19.4 months for patients of the dialysis group (interquartile range: 9.3-49.7 months), and 11.6 months for patients of the CC group (interquartile range: 3.8-30.2 months). Prior to the survey, two patients had changed their original decision to start dialysis into $\mathrm{CC}$, and one patient from CC into hemodialysis. They were analysed according to their most recent decision on preferred treatment. Of the 75 patients who selected dialysis, 34 (55\%) patients initiated dialysis in the period between original decision and the survey (median of 22.9 months between dialysis start and survey). In patients of the $\mathrm{CC}$ group, the median eGFR at the time of the survey was $15.0 \mathrm{~mL} / \mathrm{min} / 1.73 \mathrm{~m}^{2}$ (interquartile range: $12.5-20.5 \mathrm{~mL} / \mathrm{min} / 1.73 \mathrm{~m}^{2}$ ).

Table 1 shows the patient characteristics. Patients of the $\mathrm{CC}$ group were older, and lived more frequently without a partner. No significant differences were observed in sex, Davies comorbidity score, education level, and religion. Patients of the dialysis group had on average twice as many consultations about preferred treatment with the healthcare team during the shared decision-making process.

\section{Patients' satisfaction}

Figures 1 and 2 show the patients' satisfaction with the shared decision-making process, and treatment decision rated on a 11-point Likert scale. The majority reported to be satisfied with their decision-making process (\% with score 6-10, dialysis versus CC: $93 \%$ vs. $91 \%$, $P=0.06)$, and treatment choice ( $87 \%$ vs. $91 \%, P=0.03)$.

\section{Patients' experiences with shared decision-making}

Table 2 presents the findings on patients' experiences with shared decision-making on dialysis or CC (for additional findings: see Additional file 2).

\section{Preparedness for shared decision-making}

The majority of both patient groups answered they had no prior thoughts on preferred treatment before counselling started (dialysis versus CC: $63 \%$ vs. $71 \%$ ). They had never heard of dialysis before, perceived it as irrelevant to think about it yet: "When there are no 
Table 1 Patient characteristics

\begin{tabular}{|c|c|c|c|}
\hline & $\begin{array}{l}\text { Choice for } \\
\text { dialysis } \\
(n=75)\end{array}$ & $\begin{array}{l}\text { Choice for } \\
\text { conservative care } \\
(n=24)\end{array}$ & $P$ value \\
\hline Mean age (years) & $79.8 \pm 4.3$ & $84.2 \pm 4.9$ & $<0.001$ \\
\hline Female & $21(28 \%)$ & $11(46 \%)$ & 0.10 \\
\hline $\begin{array}{l}\text { Davies comorbidity } \\
\text { score }\end{array}$ & & & 0.88 \\
\hline No comorbidity & $9(12 \%)$ & $2(8 \%)$ & \\
\hline $\begin{array}{l}\text { Intermediate } \\
\text { comorbidity }\end{array}$ & $44(59 \%)$ & $15(63 \%)$ & \\
\hline Severe comorbidity & $22(29 \%)$ & $7(29 \%)$ & \\
\hline $\begin{array}{l}\text { Currently living } \\
\text { with partner }\end{array}$ & $48 / 70(69 \%)^{a}$ & $10 / 23(44 \%)^{a}$ & 0.03 \\
\hline Stated to be religious & $55 / 74(74 \%)^{a}$ & $17(71 \%)$ & 0.74 \\
\hline Education level $^{b}$ & & & 0.15 \\
\hline Primary education & $16 / 73(22 \%)^{a}$ & $10(42 \%)$ & \\
\hline Secondary education & $44 / 73(60 \%)^{a}$ & $10(42 \%)$ & \\
\hline Tertiary education & $13 / 73(18 \%)^{a}$ & $4(17 \%)$ & \\
\hline $\begin{array}{l}\text { Time since original } \\
\text { treatment decision }\end{array}$ & & & 0.04 \\
\hline$<6$ months & $7(9 \%)$ & $8(33 \%)$ & \\
\hline $6-12$ months & $18(24 \%)$ & $4(17 \%)$ & \\
\hline $12-24$ months & $21(28 \%)$ & $5(21 \%)$ & \\
\hline$>24$ months & $29(39 \%)$ & 7 (29\%) & \\
\hline $\begin{array}{l}\text { Current treatment } \\
\text { modality }\end{array}$ & $\begin{array}{l}41(55 \%) \\
\text { pre-dialysis } \\
24(32 \%) \\
\text { hemodialysis } \\
10(13 \%) \\
\text { peritoneal dialysis }\end{array}$ & $\begin{array}{l}24(100 \%) \\
\text { conservative care }\end{array}$ & \\
\hline $\begin{array}{l}\text { Median number of } \\
\text { consultations about } \\
\text { preferred treatment } \\
\text { between patient and } \\
\text { healthcare team }\end{array}$ & $\begin{array}{l}4 \\
\text { (interquartile } \\
\text { range: } 3-5 ; \\
\text { minimum: } 2 ; \\
\text { maximum: 14) }\end{array}$ & $\begin{array}{l}2 \\
\text { (interquartile } \\
\text { range: 1-6; } \\
\text { minimum: 1; } \\
\text { maximum: 11) }\end{array}$ & 0.002 \\
\hline $\begin{array}{l}\text { Interviewer- } \\
\text { administration } \\
\text { of questionnaire }\end{array}$ & $26(35 \%)$ & $6(25 \%)$ & 0.38 \\
\hline
\end{tabular}

Values are numbers (\%) unless stated otherwise

athe total number of patients is lower due to missing answers for this variable beducation level is based on the International Standard Classification of Education [53]

clinical signs or symptoms, it [treatment] is far from being on your mind" (dialysis patient), or had been postponing decision-making: "[I had] previously thought about it, but [it] was not an issue yet, so [I] pushed it as far away as possible" (dialysis patient). Patients also described wrong expectations about the disease course: "II] had never thought it [dialysis] would become really necessary for me" (dialysis patient), or unawareness of their disease: "[It] was a surprise to hear that my kidneys were functioning so badly" (CC patient). Patients from the dialysis group who did have prior thoughts on preferred treatment experienced a lack of choice and did not see any alternatives than to undergo dialysis, while some were positive to do everything possible. Such patients from the CC group considered dialysis as too burdensome.

\section{Timing of shared decision-making}

Both patient groups reported that counselling on treatment plan was started at the right time (90\% vs. $91 \%)$, and that there had been enough time to make a decision (79\% vs. $87 \%$ ). Those answering negatively would have preferred more time to consider their situation more extensively, to prepare themselves better: "[Counselling] should have started much earlier, I was shocked when I heard about it [dialysis]. The doctor should have acted more in advance" (dialysis patient), or to still be able to actively try to delay further deterioration of their kidney function: "I would have paid more attention to my health, with better diet. [I] would have been confronted with the consequences of my declining kidney function earlier" (dialysis patient), although some acknowledged that their clinical condition restricted time for decisionmaking. Four patients stated counselling had been started too early because dialysis initiation was still not needed, or they experienced stress about the potential start: "II have] mixed feelings, it [counselling] will always be unexpected. I know it for about a year now and think at each hospital visit: what are they going to say?" (choice for dialysis).

One third of the patients who had chosen dialysis reported they had felt forced to make a decision, compared to almost none of who had chosen CC (31\% vs. $5 \%, P=0.01)$. Most patients mentioned to have felt forced due to the circumstances, such as deteriorating health or kidney function, or by their nephrologist. Some mentioned their relatives, or a perceived lack of choice. Less patients of the dialysis group remembered if the possibility of postponing a decision was mentioned (39\% vs. $71 \%, P=0.008$ ).

\section{Informing shared decision-making}

Both patient groups answered they had received enough information to make a decision ( $81 \%$ vs. $73 \%)$. However, relatively more patients who had chosen $\mathrm{CC}$ indicated to have missed information ( $6 \%$ vs. $17 \%, P=0.18$ ). They preferred more information about the different treatment options, the trajectory from preparation of dialysis treatment-including the shunt operation-until start, and possible symptoms at low kidney function.

Half of the patients who had chosen dialysis remembered that withholding dialysis was discussed as treatment option, against most patients who had chosen CC (50\% vs. $86 \%, P=0.002)$. One CC patient answered that treatment options other than $\mathrm{CC}$ were barely discussed. 


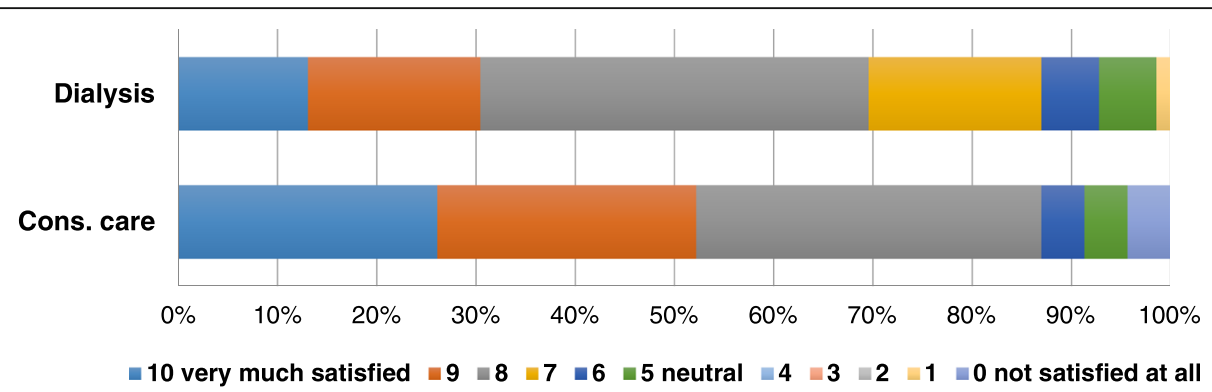

Fig. 1 Older patients' satisfaction with the shared decision-making process for choosing between dialysis and conservative care $(P=0.06)$. Rating on a 11-point Likert scale. Abbreviation: cons. care, conservative care

\section{Level of decision-making being shared}

About half of the patients who had chosen dialysis indicated their own opinion as most important in making their treatment decision, compared to almost all patients who had chosen CC (55\% vs. $90 \%, P=0.02)$. Patients of the dialysis group more frequently reported the nephrologist's or nurse's opinion (36\% vs. $11 \%)$, and of relatives (10\% vs. $0 \%$ ) as most important.

The majority reported they had experienced sufficient guidance from the healthcare team during decisionmaking (96\% vs. 95\%), and had confidence in their doctor's advice on preferred treatment (92\% vs. $78 \%$ ). Those who experienced insufficient guidance mentioned they needed more time and information. One patient answered: "In retrospect, I did not completely understand what dialysis is. An educational video using simple and comprehensible language would have been nice. Particularly because of [my] reduced capacity to process information due to my high age" (CC patient).

Most patients in both groups felt supported by their nephrologist and nurse in their decision (85\% vs. 73\%). Two patients of the CC group did not feel supported at all. Patients felt supported by their relatives (85\% vs. $82 \%)$, although explaining their choice could be difficult: "It took a lot of energy to explain our children that I deliberately opted for conservative care. At first, they did not understand it. Now they do" (CC patient).

\section{General suggestions for improvements}

Subsets of both patient groups answered that decisionmaking could have been better (12\% vs. $21 \%)$. Suggested improvements were: more information on all treatment options, tailoring of information to an individual's situation, and more time, deliberation, and involvement in decision-making.

\section{Current doubts about treatment choice}

Twelve patients who had chosen dialysis answered to still have doubts about their treatment decision at the moment of the survey, compared to none of who had chosen CC $(17 \%$ vs. $0 \%, P=0.03)$. These patients were reconsidering their decision: "Should I really do it [dialysis] considering my age?" (still pre-dialysis), or doubting which dialysis modality would be best: "Whether or not to start dialysis is not difficult, but if I can do everything on my own is uncertain" (choice for peritoneal dialysis). One patient indicated to regret his decision to start dialysis: "[I] do not know if I want to live longer, [I] would rather have died back then [before start]". Another patient did not doubt his decision for dialysis, although: "If I would have to decide again: [I would choose to] withhold dialysis. [My] health has deteriorated a lot. Four years ago, I felt much more vital".

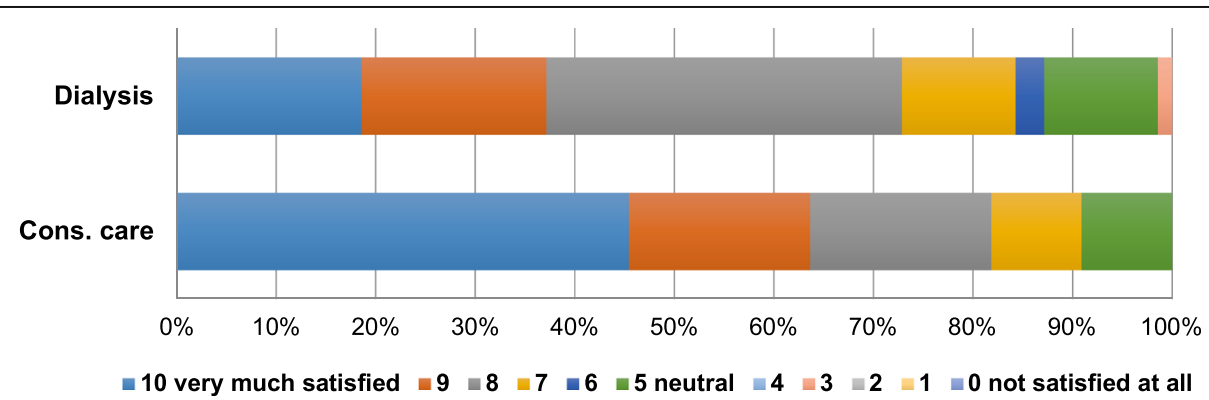

Fig. 2 Older patients' satisfaction with their treatment decision $(P=0.03)$. Rating on a 11-point Likert scale. Abbreviation: cons. care, conservative care 
Table 2 Older patients' experiences with the shared decision-making process on choosing dialysis or conservative care

\begin{tabular}{|c|c|c|c|}
\hline & $\begin{array}{l}\text { Choice for dialysis } \\
(n=75)\end{array}$ & $\begin{array}{l}\text { Choice for } \\
\text { conservative care } \\
(n=24)\end{array}$ & $P$ value \\
\hline Did you have prior thoughts on preferred treatment before counselling started? ${ }^{\mathrm{a}}$ & $27 / 74(37 \%)$ & $7 / 24(29 \%)$ & 0.51 \\
\hline Do you think counselling was started at the right time? ${ }^{a}$ & $63 / 70(90 \%)$ & 19/21 (91\%) & 1.00 \\
\hline Do you think there was enough time to make a treatment decision? & & & 0.66 \\
\hline Positive answer & $57 / 72(79 \%)$ & $20 / 23(87 \%)$ & \\
\hline Neutral answer & $14 / 72(19 \%)$ & $3 / 23(13 \%)$ & \\
\hline Negative answer & $1 / 72(1 \%)$ & $0 / 23(0 \%)$ & \\
\hline Did you feel forced to make a decision? ${ }^{\mathrm{a}}$ & $23 / 74(31 \%)$ & $1 / 22(5 \%)$ & 0.01 \\
\hline Was the possibility mentioned to postpone a decision? ${ }^{a}$ & $28 / 72(39 \%)$ & $15 / 21(71 \%)$ & 0.008 \\
\hline Do you think you had enough information to choose whether or not to start dialysis? & & & 0.23 \\
\hline Positive answer & $59 / 73(81 \%)$ & $16 / 22(73 \%)$ & \\
\hline Neutral answer & $14 / 73(19 \%)$ & $5 / 22(23 \%)$ & \\
\hline Negative answer & $0 / 73(0 \%)$ & $1 / 22(5 \%)$ & \\
\hline Did you miss information? ${ }^{\mathrm{a}}$ & $4 / 63(6 \%)$ & $3 / 18(17 \%)$ & 0.18 \\
\hline Was withholding dialysis discussed as treatment option? ${ }^{a}$ & $36 / 72(50 \%)$ & $19 / 22(86 \%)$ & 0.002 \\
\hline Did you receive sufficient guidance? ${ }^{a}$ & $65 / 68(96 \%)$ & $20 / 21(95 \%)$ & 1.00 \\
\hline Did you feel supported by your doctor and/or nurse in your choice? & & & 0.06 \\
\hline Positive answer & $60 / 71(85 \%)$ & $16 / 22(73 \%)$ & \\
\hline Neutral answer & $11 / 71(15 \%)$ & $4 / 22(18 \%)$ & \\
\hline Negative answer & $0 / 71(0 \%)$ & $2 / 22(9 \%)$ & \\
\hline Did you feel supported by your partner and/or relatives in your choice? & & & 0.74 \\
\hline Positive answer & $56 / 66(85 \%)$ & $18 / 22(82 \%)$ & \\
\hline Neutral answer & $10 / 66(15 \%)$ & $4 / 22(17 \%)$ & \\
\hline Negative answer & $0 / 66(0 \%)$ & $0 / 22(0 \%)$ & \\
\hline How much confidence did you have in your doctor's advice whether or not to start dialysis? & & & 0.13 \\
\hline Positive answer & $65 / 71(92 \%)$ & 18/23 (78\%) & \\
\hline Neutral answer & $6 / 71(9 \%)$ & $5 / 23(22 \%)$ & \\
\hline Negative answer & $0 / 71(0 \%)$ & $0 / 23(0 \%)$ & \\
\hline Whose opinion was most important in making your decision? (choose one) & & & 0.02 \\
\hline Myself & $34 / 62(55 \%)$ & $17 / 19(90 \%)$ & \\
\hline My nephrologist and/or nurse & $22 / 62(36 \%)$ & $2 / 19(11 \%)$ & \\
\hline My partner and/or family & $6 / 62(10 \%)$ & $0 / 19(0 \%)$ & \\
\hline Do you still have doubts about your treatment decision? ${ }^{a}$ & $12 / 70(17 \%)$ & $0 / 23(0 \%)$ & 0.03 \\
\hline Do you think decision-making could have been better? ${ }^{a}$ & $8 / 69(12 \%)$ & $4 / 19(21 \%)$ & 0.28 \\
\hline
\end{tabular}

Values are numbers (\%) of "yes" on a binary question ${ }^{a}$, or a positive (score 6-10), neutral (score 5), or negative answer (score 0-4) on a 11-point Likert scale. The total number of responses is indicated per question, excluding missing answers

abinary question (yes/no)

\section{Reasons for treatment choice}

Table 3 summarizes the patients' responses to the openended question why they had chosen dialysis or CC. Both patient groups had contrasting reasons for their treatment choice: patients who had chosen dialysis most frequently mentioned a perceived lack of choice, and life prolongation; while patients who had chosen CC most frequently mentioned the treatment burden of dialysis, its impact on their quality of life, and their age and sense of life completion.

\section{Discussion}

In this survey, we determined older patients' experiences with, and preferences for, shared decision-making on dialysis or CC. Patients indicated to be overall satisfied with their shared decision-making process, and treatment 
Table 3 Older patients' reasons for their treatment choice. Categorisation of open text responses to the question: "Why did you choose to start or withhold dialysis?"

\begin{tabular}{|c|c|}
\hline Choice for dialysis $(n=66)$ & Examples of answers \\
\hline Lack of choice $(n=28)$ & "Because I have to." \\
\hline Dialysis perceived as unavoidable & "What has to be done has to be done." \\
\hline Seeing no alternatives & "[l have] no other choice." \\
\hline Rejecting conservative care as option & "It [dialysis] was just necessary; withholding is no option." \\
\hline Not eligible for other treatment options & "I won't receive a new kidney; I just have to [start dialysis], that's just the way it is." \\
\hline Life prolongation $(n=20)$ & "[l] want to live longer." \\
\hline Doing everything to prolong life & "Withholding [dialysis] was no option, I still did not feel tired of life." \\
\hline Enjoying life & "[l am] far from finished being on this planet." \\
\hline Social consideration & "I just have to [start dialysis] for my partner and daughter." \\
\hline To be longer with family & "[l] want to live on, [l have] a lot of family." \\
\hline To take care of ill partner & "[My] husband has Alzheimer's disease, [I] want to be there for him." \\
\hline Following advice of doctor $(n=10)$ & "On the nephrologist's advice." \\
\hline $\begin{array}{l}\text { To maintain or improve quality of life or symptoms } \\
(n=6)\end{array}$ & "[My] physical condition deteriorated, [I] wanted to remain active with table tennis." \\
\hline Reconsidering or doubting choice $(n=6)$ & "I sometimes think: should I really do it [dialysis]? Age 77 years. I consider to withhold dialysis." \\
\hline \multicolumn{2}{|l|}{ Choice for conservative care $(n=21)$} \\
\hline $\begin{array}{l}\text { High treatment burden of dialysis, particularly } \\
\text { in-centre }(n=14)\end{array}$ & "[Dialysis means] too much hospital." \\
\hline Too much impact on quality of life & "No time to live normally any longer [with dialysis]." \\
\hline Loss of autonomy & "I felt reluctant to live with dialysis. [I] still am an active woman, don't want to be constrained." \\
\hline Physical burden of dialysis & "Potential side-effects of dialysis treatment." \\
\hline Feeling well without dialysis & "I still feel well, not ill." \\
\hline Not eligible for or fearing burden of home dialysis & "No option to go for home dialysis; home dialysis is probably disappointing." \\
\hline High age and sense of life completion $(n=11)$ & $\begin{array}{l}\text { "II] did not want it [dialysis], age of } 84 \text { years. [I] always thought: a human being should be allowed } \\
\text { to just die!" }\end{array}$ \\
\hline Unlikely survival benefit of dialysis $(n=3)$ & "No difference in life expectancy with or without dialysis." \\
\hline Poor health $(n=2)$ & "[My] health condition." \\
\hline Stories of other patients $(n=2)$ & $\begin{array}{l}\text { "[A] visit to the dialysis unit and talking with patients were decisive factors [to choose conservative } \\
\text { care]." }\end{array}$ \\
\hline Following advice of doctor $(n=2)$ & "[My] nephrologist has given negative advice [to start dialysis]." \\
\hline
\end{tabular}

decision. However, we observed a discrepancy between the high satisfaction and underlying negative experiences that older patients reported as well, especially patients who had chosen dialysis. Such negative experiences were related to the timing, informing, and level of decisionmaking being shared. We found that a substantial subset of patients who had chosen dialysis still doubted their treatment decision. These findings show that-despite high overall satisfaction-older patients had contrasting experiences with shared decision-making on dialysis or $\mathrm{CC}$, and the negative experiences illustrate important but modifiable barriers to an optimal shared decision-making process. We conclude that early initiation of decisionmaking is needed as in advance care planning and that shared decision-making should entail a dynamic process instead of a single point in time, including multiple interactions between patient, family and healthcare team about possible treatment and ongoing evaluation once a decision has been made.

Only few studies have assessed patients' satisfaction with shared decision-making on dialysis or $\mathrm{CC}$, or with the treatment decision. Seah et al. found all nine CC patients to be content with their decision, similar to our findings [30]. Ladin et al., however, observed low treatment satisfaction in dialysis patients who lacked engagement during decision-making [37]. Studies including ours also show that many patients who chose dialysis doubt or regret their decision, especially if the decision was more driven by the nephrologist's preference [38-40]. No previous study directly determined patients' satisfaction with the decision-making process, but several assessed patients' experiences which give an indication. 
Consistent with our findings, patients often describe poor decision-making experiences, particularly patients on the most intensive treatment (dialysis) [16, 18, 32, 37]. Patients, including older patients, are found to desire more involvement in decision-making, which is associated with better outcomes like satisfaction, quality of life, and treatment adherence [19, 41-44].

The timing of shared decision-making is essential but there is ongoing debate what timing is best for decisionmaking processes on dialysis or CC [15-17]. Consistent with previous research $[16,19,45]$, we found indications that decision-making should be initiated earlier because older patients felt unprepared or even forced to decide. More time and interactions with the healthcare team are needed to help patients understand and cope with their situation before a decision is to be made, to absorb information during decision-making, and to deliberatively weigh benefits and burdens of treatment options against their preferences and values. We think shared decisionmaking should therefore be approached as ongoing process which has to be initiated earlier rather than at a specific point in time when a decision on treatment becomes needed. Such early decision-making also gives the possibilities to postpone or reconsider a decision, which is preferred by older patients and could help those who doubt or regret their choice [29, 34, 39]. During our review of medical records for data collection, we found eight patients who had chosen dialysis at the time of the questionnaire to have changed their decision into CC; two had already received a dialysis shunt. Ongoing evaluation of a decision is important to assure if a chosen treatment pathway is still in line with the patient's preferences as these may change, for example because of deteriorating health [19, 34, 46]. Care for older patients with advanced CKD offers valuable opportunities to timely start a dynamic process of shared decision-making because of the chronic disease course and often long-term relationships between patient and healthcare team.

To achieve decision-making to be shared, patients need to be aware that a decision is to be made and that their involvement matters. Studies including ours, however, frequently found that older patients are unaware of the need for a decision, experience a lack of choice-particularly patients who selected dialysis-and are not encouraged or enabled sufficiently enough to participate in shared decision-making [16, 18, 19, 37, 45]. We also found, consistent with previous studies, that only half of the dialysis patients indicated their own opinion as most important rather than their nephrologist's [38-40], against the vast majority of $\mathrm{CC}$ patients $[28,30]$, while a similar approach to shared decision-making was applied in all patients. The findings in the dialysis group are in agreement with studies in different populations, such as patients with cancer or other chronic diseases, showing that patients frequently experience to lack a choice and that there is a mismatch between preference for and perceived participation in decision-making in about half of the patients [47-49]. The professional's role is crucial in this but nephrologists are found to differ in their approach to shared decision-making and preferred level of patient involvement when choosing dialysis or CC $[20,21]$. We think patient involvement should be individualized, recognizing differences in patients' preferences for involvement [41, 42], though-as a minimum-clinicians should make every patient aware that a decision is to be made and that the patient's opinion is important, to offer each patient the opportunity to become involved in the decision-making about their treatment.

Patients, and their family, need information about possible treatment options to be able to decide on treatment for end-stage kidney disease. Consistent with previous studies [32, 37-39, 50], however, we observed that many patients did not remember if withholding dialysis or CC was discussed, even reported by some patients on CC. This finding might indicate that $\mathrm{CC}$ was not discussed with patients, frequently found in other studies [21, 22, $32,38,50]$, or that it remains unclear to patients that $\mathrm{CC}$ could be chosen as treatment. Influencing factors are the nephrologist's opinion about CC-some see CC as no care-and how well-established the CC pathway is in an institution [20, 21,32]. Based on current evidence [5-10], CC is a reasonable treatment option in older patients. Therefore, patients should be informed about CC as one of the possible treatment options, including an explanation of the goals of a CC pathway to prevent misbeliefs that CC is the same as 'doing nothing'.

Shared decision-making also involves the achievement to align a treatment decision with the patient's preferences and values. Both patient groups are found to have contrasting reasons for their treatment choice: patients choose dialysis because of life prolongation, and CC because of quality of life [27-34]. As patients have different considerations, counselling should be tailored to each individual and incorporate the relevant topics for that patient. More data on patient-relevant outcomes of dialysis versus CC are needed $[8,51,52]$. Prognostic tools may be useful to inform patients, their family, and clinicians on possible outcomes, although tools need to be developed for both treatment pathways and should focus on not only survival but also other patient-relevant outcomes, like quality of life, symptoms and hospitalization [53]. More importantly, the findings on patients' reasons for their treatment decision indicate that older patients with advanced CKD rather consider their values and goals towards life, quality of life, and death than having a biomedical focus including treatment effectiveness on which nephrologists base their 
decision [18, 20, 21]. A shift to a more person-centred ethos could facilitate better eliciting and understanding of patients' priorities [19].

Our study has important limitations. First, recall bias may have influenced patients' responses about their decision-making process; we cannot verify whether experiences did actually happen or how the process took place. Furthermore, the observed discrepancy between patients' satisfaction but underlying negative experiences could be explained by socially desirable responding; true satisfaction might be lower. Second, the findings reflect the experiences and preferences of a limited number of patients. We think that each negative patient experience is relevant to take into account, although some were reported by a minority. Third, the generalizability of our results may be hindered by differences in approach to shared decisionmaking and CC at other institutions. Fourth, we used a self-developed questionnaire which needs further validation and focused on patients' perspectives.

A strength is that we included both patient groups who either had chosen dialysis or CC. Except for age and living status, the groups were comparable; observed differences could not be explained by patient characteristics as comorbidity and education level. Another strength is our longstanding institutional policy to discuss both dialysis and $\mathrm{CC}$ with patients. Further exploration is needed to improve our understanding of patients' experiences and preferences, as well as the role of patients' partner and family in decision-making.

\section{Conclusions}

We found that older patients with advanced CKD had contrasting experiences with shared decision-making on dialysis or CC alongside high overall satisfaction, and identified important barriers for improvement. We conclude that early initiation of decision-making is needed as in advance care planning and that shared decision-making should entail a dynamic process instead of a single point in time. Such approach to shared decision-making will help to achieve the overall goal to collaboratively decide by patient and professional on a treatment pathway that fits best with the patient.

\section{Additional files}

Additional file 1: Questionnaire on patients' experiences with, and preferences for, shared decision-making on dialysis or conservative care. (PDF $272 \mathrm{~kb}$ )

Additional file 2: Additional results of the questionnaire on older patients' experiences with shared decision-making on dialysis or conservative care. (PDF $335 \mathrm{~kb}$ )

\section{Abbreviations}

CC: Conservative care; CKD: Chronic kidney disease; IBM SPSS: International Business Machines Statistical Package for the Social Science; Vs: versus

\section{Acknowledgements}

We thank the patient representatives and the Dutch Kidney Patients Association (Nierpatiënten Vereniging Nederland) for their input in designing the study, developing the questionnaire, and interpreting the results.

\section{Authors' contributions}

Research idea and study design: WV, KP, JVD, WB; data acquisition: WV, JD; data analysis and interpretation: WV, WK, KP, JD, MR, JVD, WB; statistical analysis: WV, JVD, WB; supervision or mentorship: JVD, WB. All authors read and approved the final manuscript.

\section{Funding}

The study was funded by unrestricted grants from the St. Antonius Research Fund, from Roche to the St. Antonius Research Fund, and from Zilveren Kruis. The funders played no role in study design; collection, analysis, and interpretation of data; writing of the report; or in the decision to submit the report for publication.

\section{Availability of data and materials}

The datasets used and/or analysed during the current study are available from the corresponding author on reasonable request.

\section{Ethics approval and consent to participate}

Ethical approval was obtained from the local research ethics committee (Verenigde Commissies Mensgebonden Onderzoek; reference W14.053). Informed written consent was obtained from patients prior to data collection.

\section{Consent for publication}

not applicable.

\section{Competing interests}

The authors declare that they have no competing interests.

\section{Author details}

${ }^{1}$ Department of Internal Medicine, St Antonius Hospital, Koekoekslaan 1, 3435 CM Nieuwegein, The Netherlands. ${ }^{2}$ Dutch Kidney Patients Association (NVN), Bussum, The Netherlands. ${ }^{3}$ University Medical Centre Utrecht, Julius Centre for Health Sciences and Primary Care, Utrecht, The Netherlands. ${ }^{4}$ Department of Internal Medicine, Leiden University Medical Center, Leiden, The Netherlands.

Received: 30 January 2019 Accepted: 17 June 2019

Published online: 16 July 2019

\section{References}

1. Couser WG, Remuzzi G, Mendis S, Tonelli M. The contribution of chronic kidney disease to the global burden of major noncommunicable diseases. Kidney Int. 2011;80(12):1258-70.

2. Xie Y, Bowe B, Mokdad AH, Xian H, Yan Y, Li T, et al. Analysis of the global burden of disease study highlights the global, regional, and national trends of chronic kidney disease epidemiology from 1990 to 2016. Kidney Int. 2018;94(3):567-81

3. Kallenberg MH, Kleinveld HA, Dekker FW, van Munster BC, Rabelink TJ, van Buren $M$, et al. Functional and cognitive impairment, frailty, and adverse health outcomes in older patients reaching ESRD-A systematic review. Clin J Am Soc Nephrol. 2016;11(9):1624-39.

4. Berger JR, Hedayati SS. Renal replacement therapy in the elderly population. Clin J Am Soc Nephrol. 2012;7(6):1039-46.

5. Davison SN, Levin A, Moss AH, Jha V, Brown EA, Brennan F, et al. Executive summary of the KDIGO controversies conference on supportive Care in Chronic Kidney Disease: developing a roadmap to improving quality care. Kidney Int. 2015;88(3):447-59.

6. Brown MA, Collett GK, Josland EA, Foote C, Li Q, Brennan FP. CKD in elderly patients managed without dialysis: survival, symptoms, and quality of life. Clin J Am Soc Nephrol. 2015;10(2):260-8.

7. Verberne WR, Geers AB, Jellema WT, Vincent HH, van Delden JJ, Bos WJ. Comparative survival among older adults with advanced kidney disease managed conservatively versus with Dialysis. Clin J Am Soc Nephrol. 2016; 11(4):633-40. 
8. Verberne WR, Dijkers J, Kelder JC, Geers ABM, Jellema WT, Vincent HH, et al. Value-based evaluation of dialysis versus conservative care in older patients with advanced chronic kidney disease: a cohort study. BMC Nephrol. 2018; 19(1):205.

9. O'Connor NR, Kumar P. Conservative management of end-stage renal disease without dialysis: a systematic review. J Palliat Med. 2012;15(2):228-35.

10. Wongrakpanich S, Susantitaphong $P$, Isaranuwatchai S, Chenbhanich J, Eiam-Ong S, Jaber BL. Dialysis therapy and conservative Management of Advanced Chronic Kidney Disease in the elderly: a systematic review. Nephron. 2017:137(3):178-89.

11. Renal Physicians Association. Shared Decision-Making in the Appropriate Initiation of and Withdrawal from Dialysis (Clinical Practice Guideline). 2nd ed. Rockville; 2010

12. Williams AW, Dwyer AC, Eddy AA, Fink JC, Jaber BL, Linas SL, et al. Critical and honest conversations: the evidence behind the "choosing wisely" campaign recommendations by the American Society of Nephrology. Clin J Am Soc Nephrol. 2012;7(10):1664-72.

13. Farrington K, Covic A, Aucella F, Clyne N, de Vos L, Findlay A, et al. Clinical Practice Guideline on management of older patients with chronic kidney disease stage $3 b$ or higher (eGFR $<45 \mathrm{~mL} / \mathrm{min} / 1.73 \mathrm{~m} 2$ ). Nephrol Dial Transplant. 2016:31(suppl 2):ii1-ii66.

14. Koncicki HM, Schell JO. Communication skills and decision making for elderly patients with advanced kidney disease: a guide for nephrologists. Am J Kidney Dis. 2016;67(4):688-95

15. Rosansky SJ, Schell J, Shega J, Scherer J, Jacobs L, Couchoud C, et al. Treatment decisions for older adults with advanced chronic kidney disease. BMC Nephrol. 2017;18(1):200.

16. Morton RL, Tong A, Howard K, Snelling P, Webster AC. The views of patients and carers in treatment decision making for chronic kidney disease: systematic review and thematic synthesis of qualitative studies. BMJ. 2010;340:c112.

17. Mandel El, Bernacki RE, Block SD. Serious illness conversations in ESRD. Clin J Am Soc Nephrol. 2017;12(5):854-63.

18. Hussain JA, Flemming K, Murtagh FE, Johnson MJ. Patient and health care professional decision-making to commence and withdraw from renal dialysis: a systematic review of qualitative research. Clin J Am Soc Nephrol. 2015;10(7):1201-15.

19. Bunn F, Goodman C, Russell B, Wilson P, Manthorpe J, Rait G, et al. Supporting shared decision making for older people with multiple health and social care needs: a realist synthesis. BMC Geriatr. 2018;18(1):165.

20. Ladin K, Pandya R, Perrone RD, Meyer KB, Kannam A, Loke R, et al. Characterizing approaches to Dialysis decision making with older adults: a qualitative study of nephrologists. Clin J Am Soc Nephrol. 2018;13(8):1188-96.

21. Ladin K, Pandya R, Kannam A, Loke R, Oskoui T, Perrone RD, et al. Discussing conservative management with older patients with CKD: an interview study of nephrologists. Am J Kidney Dis. 2018;71(5):627-35.

22. van de Luijtgaarden MW, Noordzij M, van Biesen W, Couchoud C, Cancarini G, Bos WJ, et al. Conservative care in Europe--nephrologists' experience with the decision not to start renal replacement therapy. Nephrol Dial Transplant. 2013;28(10):2604-12

23. van Loon IN, Boereboom FT, Bots ML, Verhaar MC, Hamaker ME. A national survey on the decision-making process of dialysis initiation in elderly patients. Neth J Med. 2015;73(5):227-35.

24. Schell JO, Patel UD, Steinhauser KE, Ammarell N, Tulsky JA. Discussions of the kidney disease trajectory by elderly patients and nephrologists: a qualitative study. Am J Kidney Dis. 2012;59(4):495-503.

25. Wachterman MW, Marcantonio ER, Davis RB, Cohen RA, Waikar SS, Phillips $\mathrm{RS}$, et al. Relationship between the prognostic expectations of seriously ill patients undergoing hemodialysis and their nephrologists. JAMA Intern Med. 2013:173(13):1206-14.

26. van Biesen W, van de Luijtgaarden MW, Brown EA, Michel JP, van Munster BC, Jager KJ, et al. Nephrologists' perceptions regarding dialysis withdrawal and palliative care in Europe: lessons from a European renal best practice survey. Nephrol Dial Transplant. 2015;30(12):1951-8.

27. Ashby M, op't Hoog C, Kellehear A, Kerr PG, Brooks D, Nicholls K, et al. Renal dialysis abatement: lessons from a social study. Palliat Med. 2005;19(5):389-96.

28. Johnston $\mathrm{S}$, Noble $\mathrm{H}$. Factors influencing patients with stage 5 chronic kidney disease to opt for conservative management: a practitioner research study. J Clin Nurs. 2012;21(9-10):1215-22.

29. Noble H, Meyer J, Bridges J, Kelly D, Johnson B. Reasons renal patients give for deciding not to dialyze: a prospective qualitative interview study. Dial Transplant. 2009;38(3):82-9.
30. Seah AS, Tan F, Srinivas S, Wu HY, Griva K. Opting out of dialysis exploring patients' decisions to forego dialysis in favour of conservative non-dialytic management for end-stage renal disease. Health Expect. 2013;18(5):1018-29.

31. Chanouzas D, Ng KP, Fallouh B, Baharani J. What influences patient choice of treatment modality at the pre-dialysis stage? Nephrol Dial Transplant. 2012;27(4):1542-7.

32. Tonkin-Crine S, Okamoto I, Leydon GM, Murtagh FE, Farrington K, Caskey F, et al. Understanding by older patients of Dialysis and conservative Management for Chronic Kidney Failure. Am J Kidney Dis. 2014;65(3):443-50.

33. Visser A, Dijkstra GJ, Kuiper D, de Jong PE, Franssen CF, Gansevoort RT, et al. Accepting or declining dialysis: considerations taken into account by elderly patients with end-stage renal disease. J Nephrol. 2009;22(6):794-9.

34. Lovell S, Walker RJ, Schollum JB, Marshall MR, McNoe BM, Derrett S. To dialyse or delay: a qualitative study of older new Zealanders' perceptions and experiences of decision-making, with stage 5 chronic kidney disease. BMJ Open. 2017;7(3):e014781.

35. International Standard Classification of Education (ISCED 2011) [Available from: http://uis.unesco.org/en/topic/international-standard-classificationeducation-isced. Accessed 28 Jan 2019.

36. Davies SJ, Russell L, Bryan J, Phillips L, Russell Gl. Comorbidity, urea kinetics, and appetite in continuous ambulatory peritoneal dialysis patients: their interrelationship and prediction of survival. Am J Kidney Dis. 1995;26(2):353-61.

37. Ladin K, Lin N, Hahn E, Zhang G, Koch-Weser S, Weiner DE. Engagement in decision-making and patient satisfaction: a qualitative study of older patients' perceptions of dialysis initiation and modality decisions. Nephrol Dial Transplant. 2017:32(8):1394-401.

38. Gilman EA, Feely MA, Hildebrandt D, Edakkanambeth Varayil J, Chong EY, Williams AW, et al. Do patients receiving hemodialysis regret starting dialysis? A survey of affected patients. Clin Nephrol. 2017;87(3):117-23.

39. Davison SN. End-of-life care preferences and needs: perceptions of patients with chronic kidney disease. Clin J Am Soc Nephrol. 2010;5(2):195-204.

40. Berkhout-Byrne N, Gaasbeek A, Mallat MJK, Rabelink TJ, Mooijaart SP, Dekker FW, et al. Regret about the decision to start dialysis: a cross-sectional Dutch national survey. Neth J Med. 2017;75(6):225-34.

41. Wolff JL, Boyd CM. A look at person- and family-centered care among older adults: results from a National Survey [corrected]. J Gen Intern Med. 2015; 30(10):1497-504.

42. Chewning B, Bylund CL, Shah B, Arora NK, Gueguen JA, Makoul G. Patient preferences for shared decisions: a systematic review. Patient Educ Couns. 2012;86(1):9-18.

43. Mechta Nielsen T, Frøjk Juhl M, Feldt-Rasmussen B, Thomsen T. Adherence to medication in patients with chronic kidney disease: a systematic review of qualitative research. Clin Kidney J. 2018;11(4):513-27.

44. Shay LA, Lafata JE. Where is the evidence? A systematic review of shared decision making and patient outcomes. Med Decis Mak. 2015;35(1):114-31.

45. Joseph-Williams N, Elwyn G, Edwards A. Knowledge is not power for patients: a systematic review and thematic synthesis of patient-reported barriers and facilitators to shared decision making. Patient Educ Couns. 2014;94(3):291-309.

46. Bratzke LC, Muehrer RJ, Kehl KA, Lee KS, Ward EC, Kwekkeboom KL. Self-management priority setting and decision-making in adults with multimorbidity: a narrative review of literature. Int J Nurs Stud. 2015; 52(3):744-55.

47. Tariman JD, Berry DL, Cochrane B, Doorenbos A, Schepp K. Preferred and actual participation roles during health care decision making in persons with cancer: a systematic review. Ann Oncol. 2010;21(6):1145-51.

48. Brom L, Hopmans W, Pasman HR, Timmermans DR, Widdershoven GA, Onwuteaka-Philipsen BD. Congruence between patients' preferred and perceived participation in medical decision-making: a review of the literature. BMC Med Inform Decis Mak. 2014;14:25.

49. Hirpara DH, Cleghorn MC, Sockalingam S, Quereshy FA. Understanding the complexities of shared decision-making in cancer: a qualitative study of the perspectives of patients undergoing colorectal surgery. Can J Surg. 2016; 59(3):197-204.

50. Song MK, Lin FC, Gilet CA, Arnold RM, Bridgman JC, Ward SE. Patient perspectives on informed decision-making surrounding dialysis initiation. Nephrol Dial Transplant. 2013;28(11):2815-23.

51. Parvez S, Abdel-Kader K, Pankratz VS, Song MK, Unruh M. Provider knowledge, attitudes, and practices surrounding conservative Management for Patients with advanced CKD. Clin J Am Soc Nephrol. 2016;11(5):812-20. 
52. Grubbs V, Tuot DS, Powe NR, O'Donoghue D, Chesla CA. System-level barriers and facilitators for foregoing or withdrawing Dialysis: a qualitative study of nephrologists in the United States and England. Am J Kidney Dis. 2017;70(5):602-10

53. Couchoud C, Hemmelgarn B, Kotanko P, Germain MJ, Moranne O, Davison SN. Supportive care: time to change our prognostic tools and their use in CKD. Clin J Am Soc Nephrol. 2016;11(10):1892-901.

\section{Publisher's Note}

Springer Nature remains neutral with regard to jurisdictional claims in published maps and institutional affiliations.

Ready to submit your research? Choose BMC and benefit from:

- fast, convenient online submission

- thorough peer review by experienced researchers in your field

- rapid publication on acceptance

- support for research data, including large and complex data types

- gold Open Access which fosters wider collaboration and increased citations

- maximum visibility for your research: over $100 \mathrm{M}$ website views per year

At BMC, research is always in progress.

Learn more biomedcentral.com/submissions 